\title{
An update on mindfulness meditation as a self-help treatment for anxiety and depression
}

This article was published in the following Dove Press journal:

Psychology Research and Behavior Management

19 October 2012

Number of times this article has been viewed

\section{Teresa M Edenfield \\ Sy Atezaz Saeed}

Department of Psychiatric Medicine, Brody School of Medicine at East Carolina University, Greenville, NC, USA
Correspondence: Teresa M Edenfield

Durham VAMC, Psychology (I I6B), 508

Fulton Street, Durham, NC 27705, USA

Tel + I 91928604 II ext 6705

$\mathrm{Fax}+19194165927$

Email teresa.edenfield@va.gov
Abstract: In recent years, complementary and alternative medicine (CAM) treatments have increased in popularity. This is especially true for treatments that are related to exercise and mindfulness-based interventions (MBIs) in the treatment of both mental and physical illness. MBIs, such as Mindfulness-based Cognitive Therapy (MBCT) and Mindfulness-Based Stress Reduction (MBSR), which are derived from ancient Buddhist and Yoga philosophies, have become popular treatments in contemporary psychotherapy. While there is growing evidence that supports the role of these interventions in relapse prevention, little is known about the role that MBIs play in the treatment of acute symptoms of depression and anxiety. Even less is known about the importance of specific components of MBIs (eg, mindfulness meditation [MM]) and the overall impact that these interventions have on the experience or expression of psychological distress. Moreover, few studies have rigorously evaluated the dose-response relationship that is required to effect positive symptom change and the mechanisms of change that are responsible for observed improvements. This review will define meditation and mindfulness, discuss the relationship between stress and health and how MM relates to therapeutically engaging the relaxation response, and review the empirical findings that are related to the efficacy of MM in the treatment of depression and anxiety symptoms. Given the paucity of research that examines the applications of these treatments in clinical populations, the limitations of applying these findings to clinical samples will be mentioned. A brief review of the issues related to the possible mechanisms of change and the dose-response relationship regarding MBIs, particularly MM, will be provided. Finally, limitations of the extant literature and future directions for further exploration of this topic will be offered.

Keywords: mindfulness-based interventions, mindfulness meditation, mindfulness-based stress reduction, mindfulness for depression, mindfulness for anxiety

\section{Introduction}

In recent years, complementary and alternative medicine (CAM) treatments have grown in popularity. Particularly, there has been an increase in research related to the use of exercise in treating depression and other psychological conditions; ${ }^{1-5}$ additionally, there has been an increase in literature that examines mindfulness-based interventions (MBIs) in the treatment of both mental and physical illness (for reviews see ${ }^{6-9}$ ). Over the past two decades, research on MBIs, particularly their effectiveness in treating symptoms of depression, anxiety, and various stress-related physical symptoms and conditions, has increased significantly. Other areas of investigation include the use of exercise, yoga, acupuncture, and non-FDA-approved agents in the treatment of anxiety and depression. ${ }^{10,11}$ 
Despite a relative lack of methodologically rigorous investigations into CAM treatments (including MBIs), their popularity, particularly in Western cultures, has increased. Some evidence suggests these treatments may be preferred by consumers relative to mainstream approaches (eg, psychotherapy, approved psychotropic medications). ${ }^{12} \mathrm{MBIs}$, such as Mindfulness-Based Cognitive Therapy (MBCT) ${ }^{13}$ and Mindfulness-Based Stress Reduction (MBSR), ${ }^{14}$ which are both grounded in ancient Buddhist and Yoga philosophies, have become popular treatments in contemporary psychotherapy. ${ }^{6,15-18}$ To date, applications have primarily focused on relapse prevention rather than treatment of acute symptomatology. ${ }^{13,14,19-23}$ Also, little is known about the role of MBIs, including the meditation component, in the treatment of acute symptoms of depression and anxiety, and little work has been done to investigate the dose-response relationship that is required to effect positive changes or regarding the mechanisms of change that may be responsible for the observed improvements in both the mental and physical well-being with MBIs. Psychotherapeutic interventions such as Acceptance and Commitment Therapy (ACT) $)^{24}$ and dialectical behavior therapy (DBT) ${ }^{25}$ are consistent with modern conceptualizations of mindfulness; however, these treatment approaches only partially incorporate formal meditation training and differ significantly from other MM practices. ${ }^{26,27}$ However, while mentioning these interventions is important, they will not be the focus of this review.

In this review, we will define meditation and mindfulness, as well as discuss the relationship between stress and health and how meditation relates to therapeutically engaging the relaxation response. In addition, this review will present an overview of the empirical findings that are related to the efficacy of MM in the treatment of depression and anxiety symptoms. Given the paucity of research using clinical populations, the limitations of applying findings to clinical samples is also mentioned. This will be followed by a brief review of the issues that are related to the possible mechanisms of change. The dose-response relationship of MBIs will also be provided. Finally, this review will conclude with an examination of the limitations and future developments of this research topic.

\section{Defining meditation and mindfulness}

Meditation is defined as the intentional self-regulation of attention from moment to moment. ${ }^{28,29}$ It is an intentional and self-regulated focusing of attention for the purpose of relaxing and calming the mind and body. The word itself is derived from two Latin words: "meditari" - to think, to dwell upon, or to exercise the mind, and "mederi" - to heal. The Sanskrit derivation is "medha," which means "wisdom." The practice of meditation originates in Asian cultures and is historically known as a core component in many spiritual practices (eg, Buddhism). Western cultures have popularized the techniques over the last few decades, and, since the 1960s, there has been increasing research attention paid to meditative practices. Various physical and psychological health changes (eg, increased cerebral blood flow; reductions in metabolic activity, heart and respiratory rates, blood pressure, oxygen consumption, and muscle tension; decreased depression and anxiety symptoms) have been empirically linked to the practice of meditation, particularly $\mathrm{MM} \cdot{ }^{30-35}$

Although there are various styles of meditation, including Chakra yoga, Rinzai Zen, Mudra yoga, Sufism, Yoto Zen, and Buddhist insight meditation, two of the more commonly discussed forms of meditation are transcendental meditation (TM) and mindfulness meditation (MM). TM, founded by the Yogi Maharishi Mahesh in 1957, is a concentrative form of meditation that trains its participants to restrict the focus of attention to a single stimulus (eg, a word or mantra, a sound, object, or sensation). When attention wanders, it is redirected to the object of meditation and no attention is paid to the nature of the distraction. Concentrative forms of meditation are used to attain a state of physical relaxation, calm, and enlightenment. TM will not be the focus of this review, as it has been reviewed elsewhere in the literature. . $^{36,37}$

Mindfulness refers to the process of intentionally bringing one's attention, in a nonjudgmental manner, to the internal and external experiences that exist in the present moment. This may include awareness of sensations, thoughts, bodily states, consciousness, and the environment, while simultaneously encouraging openness, curiosity, and acceptance. It is often taught through a variety of meditation exercises. ${ }^{6,9,15,38,39}$ Marlatt and Kristeller defined mindfulness as "bringing one's complete attention to the present experience on a momentto-moment basis." ${ }^{40}$ Kabat-Zinn wrote that mindfulness is "paying attention in a particular way: on purpose, in the present moment, and nonjudgmentally." 17

Improved mindfulness can be achieved through the regular practice of meditation. MM, which is the core focus of this review, originates from Eastern contemplative practices and typically involves exercises, such as body scan, as well as walking and seated meditations. MM is intended to cultivate continuous and clear attention to ongoing subjective experiences, combined with an attitude of acceptance and openness to whatever experiences may arise. MM is included as a core 
component of many contemporary forms of psychotherapy (eg, MBSR, MBCT, Mindfulness-Based Eating Awareness Training [MB-EAT]). ${ }^{13,14,21,23}$ According to advocates of MM, distracting thoughts and feelings are not ignored but are acknowledged and observed in a nonjudgmental manner as they arise. This allows the individual to detach from them for the purpose of gaining insight, awareness, compassion, and facilitate more flexible and adaptive coping responses. Researchers believe that cultivation of such characteristics can assist individuals in actualizing a greater sense of well-being and health. It involves a process of allowing the mind to be "still," so that the mind's habitual patterns are suspended to allow for greater awareness of the present moment. Contrary to popular beliefs, MM is not an act of worship or a prayer; rather, it is taught independently of the spiritual and cultural traditions from which they originate. ${ }^{25,29}$ For example, so long as there is intention to open and enhance one's awareness of the present moment, the practice of "watching your breath" is as much meditation as is attending to the sounds of nature, the sensations of the body during an eating episode, or a guided body scan. Key elements of mindfulness include the following: the ability to intentionally attend to the present moment regardless of the content observed, ${ }^{38}$ the ability to recognize and accurately label emotions, ${ }^{41}$ and a more refined self-awareness. ${ }^{38}$

Bishop et $\mathrm{al}^{15}$ distinguished two core components of mindfulness: (1) self-regulation of attention, and (2) orientation toward the present moment characterized by curiosity, openness, and acceptance. The basic premise underlying mindfulness practices is that experiencing the present moment, openly and without judgment, will counter the effects of stress that often results from excessive orientation toward the past or future that is often observed in anxious and depressive conditions. ${ }^{38}$ Moreover, it is believed that teaching an individual to respond to stress reflectively, rather than reflexively, will counter experiential avoidance strategies. Experiential avoidance strategies are viewed as attempts to alter the intensity or frequency of undesirable or unwanted internal experiences ${ }^{42}$ and are maladaptive strategies (eg, future/past orientation, experiential avoidance) that have been shown to contribute to the onset and maintenance of many, if not most, emotional disorders. ${ }^{15,16}$ The slow and deep breathing strategies involved in MM (eg, sitting meditation, Hatha yoga, body scan in MBSR) ${ }^{29}$ are thought to alleviate bodily symptoms of distress by balancing sympathetic and parasympathetic responses (described below). ${ }^{38}$ As indicated above, the research regarding specific mechanisms of change and rigorous clinical trials of MBIs, particularly sub-components of intervention, such as MM, is limited. However, a number of review articles ${ }^{8,19,39,43-50}$ and meta-analyses ${ }^{6,9,51,52}$ have been published that show promise regarding the efficacy of MBIs for reducing stress, anxiety, and depression.

\section{Meditation, stress, and health}

Increasing empirical support for the therapeutic effects of $\mathrm{MM}$ on stress and stress-related medical conditions has been demonstrated in recent years. Specifically, the demonstrated benefits of $\mathrm{MM}$ interventions on chronic lower back pain, ${ }^{53}$ fibromyalgia, ${ }^{54}$ rheumatoid arthritis, ${ }^{55,56}$ psoriasis, ${ }^{57}$ and Type II diabetes mellitus ${ }^{58}$ are promising. In addition, in a recent review of the literature, Chiesa and Serretti ${ }^{59}$ reported that MBIs show promise in reducing perceived pain, as well as an improved ability to cope with pain and a decrease in the depressive symptoms in patients dealing with chronic pain conditions. Research has also consistently demonstrated the effectiveness of mindfulness training on stress reduction and reducing negative mood states, as well as for improving the emotional well-being and quality of life of individuals dealing with chronic physical illness (eg, hypertension, human immunodeficiency virus, depression secondary to pain). ${ }^{51,59-62}$

Various theories have attempted to define pathways that may underlie the benefits of mindfulness training; however, clear mechanisms of change have yet to be identified or empirically supported on a consistent basis. A variety of behavioral, psychological, and biological pathways have been suggested to explain how enhanced mindfulness may preempt stress-related illness, including: (1) clarification of primary appraisal of stressors; (2) facilitating accurate secondary appraisal of the demands of a given stressor and available coping resources; (3) mitigating dysfunctional coping styles (eg, cognitive distortions such as rumination and catastrophizing); (4) enhancing adaptive coping processes (eg, positive reappraisal); and (5) reducing distress and psychophysiological activation. ${ }^{63}$ The role of factors such as improved metacognition skills (eg, decentering), ${ }^{64}$ reperceiving, ${ }^{65}$ adaptive coping styles (eg, positive reappraisal), ${ }^{66}$ and decreased emotional interference ${ }^{67}$ are also thought to be beneficial.

\section{Meditation and the relaxation response}

In order to adequately decipher the proposed benefits of approaches, such as meditation, on physical and emotional health, the authors will briefly review the relationship between stress/emotional distress and the nervous system. The autonomic nervous system (ANS) is comprised of two branches that often work in opposition: the sympathetic (ergotrophic) nervous system (SNS) and the parasympathetic 
(trophotropic) nervous system (PNS), which innervate the organs, glands, and vessels. ${ }^{68}$ The SNS activates the body and releases stored energy, whereas the PNS governs relaxation, recuperation, and digestion. ${ }^{68}$ Stress networks are activated when threats (real or imagined) are perceived and activity in these networks biases respond in the direction of heightened alertness toward salient stimuli and self-protective behavior. ${ }^{69}$ This heightened autonomic arousal results in an overall feeling state of anxiety, fear, or alarm, ${ }^{70}$ which triggers an individual to engage in behaviors that reduce activity in the stress networks (either consciously or not). For a comprehensive review of the origins of developmental plasticity and human behavior, and the role of brain networks in regulation of stress reactivity, the reader is referred to the work of Crespi and Denver ${ }^{71}$ and Dallman and Hellhammer, ${ }^{72}$ respectively.

With a basic understanding of the relationship between stress and the nervous system, it is easier to understand the relaxation response or the physiological state in which the PNS is activated, which results in a drop in heart, metabolic, and breathing rates. ${ }^{2}$ This integrated set of physiological changes is closely related to the "fight or flight" response, which is governed by the SNS and is responsible for physiologic survival instincts that result in a release of hormones (eg, epinephrine, norepinephrine) that prepare the body to protect itself from a threat (ie, to fight or to flee).

The act of intentionally activating the relaxation response counteracts activation of the sympathetic nervous system in favor of the parasympathetic nervous system. Meditation involves the intentional and repeated practice of intentionally activating the body's relaxation response and has shown potential to improve one's ability to manage stress, which has been shown to underlie various physical and psychological illnesses. ${ }^{73,74}$ In early studies, Benson and Klipper ${ }^{2}$ demonstrated that humans have the capacity to intentionally induce a state of relaxation or calm that assists the body in healing and rejuvenation. This process was described as an additional but equally essential survival mechanism. Regular elicitation of the relaxation response was found to prevent and compensate for the damage that is incurred by frequent activations of the sympathetic nervous system, which may cause the body to unnecessarily remain in a state of hypervigilance or hyperarousal. $^{2}$

\section{Meditation versus relaxation}

It is important to note that MM is not the same as relaxation. While meditative practice may induce an integrated set of physiological changes (eg, lowered heart, breathing, and metabolic rates), the practice of $\mathrm{MM}$ is an active and intentional state of awareness whose purpose is not, necessarily, to induce a state of relaxation. Unlike relaxation training, MM teaches individuals to attenuate prolonged reactivity to negative stimuli, whereas relaxation training encourages distraction and sleep may not be considered as an unwelcomed outcome during practice.

\section{Efficacy of $M M$ in reducing symptoms of depression and anxiety}

Existing research on MBIs, which includes meditation, supports the theory that cultivation of greater attention, awareness, and acceptance through meditation practices is associated with lower levels of psychological distress, including decreased symptoms of depression, anxiety, worry, and anger. ${ }^{6,8,51,60,75}$ Research has also demonstrated promise for the role of MBIs in treating clinical depression, particularly regarding relapse prevention (eg, MBCT, ACT); however, relatively little work has been done to investigate the role of meditation in mediating (active/acute) negative mood symptom expression in clinical populations. To date, the majority of the literature has explored the relationship between training in mindfulness and related meditation practices in relation to coping with various stressful health conditions (eg, coronary artery disease, cancer, HIV, pain, etc), and the possible positive impact of MM on neuropsychological and cognitive processes (eg, ruminative patterns, cognitive reactivity, avoidance, anxiety sensitivity) that are well known to underlie clinical presentations of depression and anxiety disorders. ${ }^{6,15,76-78}$

\section{Use of MBIs in clinical samples}

A relatively large number of studies have examined changes in anxiety and depression symptoms in a range of psychiatric and medical disorders. Reviews of the available evidence have highlighted mixed findings regarding the efficacy of these interventions, as well as the limitations regarding the methodological rigor employed in existing studies. ${ }^{6,19}$ In 2010, Hofmann et al published results from a meta-analytic review of mindfulness-based therapy on anxiety and depression in clinical (diagnosed medical or psychological disorder) samples. ${ }^{9}$ They reviewed 39 studies, including a total of 1140 participants receiving MBIs for a range of conditions (eg, cancer, generalized anxiety disorder, depression, and other psychiatric or medical concerns). Studies were included based on these primary criteria: inclusion of an MBI, an adult (ie, ages 18-65) clinical sample (ie, diagnosable psychological or medical disorder), the MBI was not paired with ACT or DBT, the study assessed anxiety and/or mood 
symptoms pre- and posttreatment, and data were sufficient to perform effect size analyses. Calculated effect size estimates from this meta-analysis showed that MBIs were moderately effective for improving anxiety (Hedges' $g=0.63$ ) and mood symptoms (Hedges' $g=0.59$ ). In patients with diagnosed anxiety and mood disorders, the mindfulness interventions were associated with more significant improvements in symptoms of anxiety (Hedges' $g=0.97$ ) and mood (Hedges' $g=0.95)$. Effect sizes were robust and did not appear to be the result of differences in length of treatment (ie, number of sessions) or the effect of a publication bias (ie, year of publication). Moreover, improvements were maintained over extended follow-up periods (average of 27-week follow-up, median of 12 weeks). Limitations of this study include liberal selection criteria and an inability to calculate controlled effect sizes. For less than half of the trials included in the study, effect size estimates were deemed unreliable due to publication bias, with the exception of measures of anxiety symptom severity in active treatment-controlled studies. Nevertheless, pre-post treatment effects were robust, and the quality and homogeneity of the studies included in the study were considerably better than those included in other meta-analyses. ${ }^{79,80}$ In another meta-analysis of the effects of a psychological placebo in anxiety disorder treatment, effect sizes associated with mindfulness training appeared significantly greater than those associated with a placebo, with a Hedges' $g$ of 0.45 (95\% CI: $0.35-0.46) .{ }^{81}$ Nevertheless, additional research that includes rigorous methodological design is needed to determine the efficacy of MBIs for depression and anxiety, including whether a dose-response relationship exists.

\section{MBls for psychological well-being and risk reduction}

More research is available regarding the possible benefits of $\mathrm{MM}$ on reducing psychological distress and improving psychological well-being. In a recent review, Keng et al ${ }^{82}$ found that increased trait mindfulness may result in greater levels of adaptive psychological functioning. In the review, greater trait mindfulness was associated with improved subjective well-being, reduced symptoms of psychological distress, decreased emotional reactivity, and enhanced regulation of behavioral responses. Clinical trials have also demonstrated the role of MM on improving cognitive processes (eg, rumination, distraction, reshaping of thoughts) that are known to be associated with the onset, maintenance, and exacerbation of depression and anxiety. ${ }^{83-85}$ In an observational study of an 8-week, home-based, meditation intervention in which participants practiced strategies such as body scan, yoga, and sitting meditation, researchers reported increased mindfulness was associated with decreased psychological distress and improved psychological well-being based on self-report data. ${ }^{86}$ In a randomized controlled trial investigating the effects of MM on cognitive processes (eg, rumination) associated with psychological distress (eg, depression, anxiety), Jain et $\mathrm{al}^{87}$ found that a 4-week MM training intervention was superior to somatic relaxation training and nonintervention control in reducing psychological distress as a result of decreased rumination in college students. Similarly, Ramel et al reported that 8 weeks of MM training resulted in significant reductions of ruminative thinking in individuals with a history of depression. ${ }^{88}$ In a pilot study of MBSR on ruminative thinking, Deyo et $\mathrm{al}^{89}$ found that completers of the MBSR class demonstrated increased mindfulness and overall well-being, as well as decreases in ruminative thinking and depressive symptoms.

Other lines of research have shown that higher trait mindfulness, irrespective of formal meditation training, is associated with factors that may place individuals at lower risk for developing depression and anxiety disorders. Specifically, higher trait mindfulness has been associated with lower rates of perceived stress, anxiety, and depression, as well as feeling states known to be associated with emotional well-being and greater perceived quality of life (eg, joy, inspiration, gratefulness, hopefulness, contentment, vitality, and overall life satisfaction). ${ }^{90-94}$ Thompson and Waltz ${ }^{95}$ found that everyday mindfulness was positively correlated with agreeableness and conscientiousness, and negatively correlated with neuroticism. Generally, individuals with higher trait mindfulness may experience enhanced abilities to regulate emotional well-being through greater emotional awareness, understanding, acceptance, and the ability to adaptively cope with and correct unpleasant mood states. ${ }^{60,90,96}$ Moreover, the psychological benefits of being in a mindful state, even momentarily, have been shown to be associated with a greater sense of well-being. ${ }^{97}$ Mindfulness training also shows promise in the ability to effect positive changes regarding the use of maladaptive coping strategies, such as smoking, ${ }^{98}$ binge eating, ${ }^{20}$ and alcohol/substance use, ${ }^{22}$ that may contribute to both physical and psychological distress and impairment. Mindfulness training has also been shown to improve sleep quality, ${ }^{50,99}$ which can be impaired by stress, anxiety, and rumination/worry. In addition, morning cortisol levels have been shown to decrease for both novice and skilled meditators, which may be related to improved sleep quality and overall well-being related to 
stress levels. ${ }^{99}$ In summary, cultivating greater mindfulness in one's way of living has consistently been shown to result in less emotional distress, more positive states of mind, and improved overall quality of life, including physical and psychological correlates. Moreover, the ability to effectively regulate internal emotional experiences through mindful awareness and acceptance may result in greater long-term psychological well-being.

\section{Mechanisms of change}

Although the ability to understand the construct of mindfulness should be viewed as a priority as MBIs become increasingly popular, ${ }^{15}$ research specifically targeting meditation as a primary treatment (or treatment component) for depression and anxiety is somewhat limited. As indicated earlier, this is particularly true for the use of MBIs in the treatment of clinical populations. As evidence has grown demonstrating promise for MBIs, there has been a call for research to specifically address the mechanisms of change in these treatment approaches. ${ }^{65,100,101}$ Specifically, mindful breathing and meditation are core components of various mindfulness-based approaches (eg, MBSR, MBCT); however, little is known about their differential effects on factors that are known to underlie psychological illnesses (eg, the role of rumination and cognitive distortions in depression and anxiety disorders). ${ }^{83-85}$ Improved understanding of the role of MBIs in affecting positive changes on correlates and precipitants of psychological disorders (eg, rumination, negative automatic thoughts, emotional reactivity) is important in improving the translation of research to practice, specifically regarding the treatment and prevention of impairing conditions such as recurrent and chronic psychological disorders (eg, major depressive disorder, generalized anxiety disorder).

Although current research is limited, some studies have begun to investigate the causal mechanisms associated with the positive effects of MM on psychological wellbeing. The process of decentering has been emphasized in MBIs for depression. ${ }^{13}$ Through this process, patients are taught to view thoughts as events in the mind rather than treating thoughts as accurate reflections of reality, which is a cognitive style typical in individuals with depressive disorders. Some research has demonstrated that trait mindfulness may be predictive of decreased frequency of negative automatic thoughts, and higher perceived ability to disengage from negative thoughts during the practice of brief mindfulness exercises. ${ }^{102}$ Similarly, other research has examined predictors and correlates of decentering, as measured by the Toronto Mindfulness Scale (TMS), ${ }^{97}$ immediately following the practice of MM. ${ }^{67,95,97}$ While the studies contribute important findings to the literature, they do not include a control or comparison group, which limits the ability to speculate whether the observed effects are due to $\mathrm{MM}$ or other nonspecific effects (eg, individual differences in expectation, benefits of group support, history of illness).

Feldman et al ${ }^{103}$ compared the immediate effects of mindful breathing to alternative stress management techniques (progressive muscle relaxation and loving-kindness meditation) in novice meditators to test whether decentering is unique to MM or common across a number of stress management approaches. Participants were randomly assigned to one of the three conditions, and completed 15-minutes of the assigned stress management exercises guided by an audio recording. The researchers found that participants who completed the mindful breathing intervention demonstrated greater decentering when compared to those receiving the two alternative interventions; there was also reduced frequency of repetitive thoughts and negative reactions to thoughts. These findings provide further evidence that cognitive aspects of MM (eg, mindful breathing) may create changes in cognitive processes associated with depression and anxiety (eg, rumination) that are distinct from other validated stressmanagement approaches. Additional research is needed to clarify the role of decentering in mediating the frequency of negative thoughts and negative reactions to thoughts that may contribute to the onset, maintenance, and exacerbation of psychological disorders.

In addition to studies investigating cognitive constructs that may be responsible for the beneficial effects of mindfulness training on psychological well-being, the relative importance of movement/exercise in some meditative practices (eg, yoga postures and body movements that may elicit changes in heart rhythm, breathing rate, etc) is in need of research. Given the established relationship between exercise interventions as a complementary and/or alternative treatment for depression, ${ }^{1,3,5,104-107}$ anxiety, ${ }^{4,107}$ and various aspects of health and well-being, ${ }^{107-110}$ research is needed to address which factors may be most important in the treatment of depression and anxiety (clinical and subclinical), and to determine which populations may benefit most from particular interventions or interventional components. In summary, additional research is needed to clarify the mechanisms of change that are responsible for the beneficial effects of MM on both psychological and physical health. 


\section{Neurobiology and mechanisms of change}

The neurobiological underpinnings of depression and anxiety disorders have been studied in both animal and human models, and it is widely accepted that dysregulation of brain regions and structures, such as the prefrontal cortex (PFC), limbic system, amygdala, hippocampus, and hypothalamopituitary-adrenal axis, are associated with depression and anxiety. ${ }^{11-113}$ Similarly, it has been shown that chronic stress may evoke neurobiological changes that mirror those seen in depression. ${ }^{68}$

Although the study of neurophysiological changes in the brain associated with meditation is in its infancy, a number of studies have been conducted in recent years that investigate the impact of mindfulness training and meditation on brain regions responsible for constructs that are often dysregulated in individuals with depressive and anxiety disorders, including attention regulation, awareness, and emotional reactivity. ${ }^{14,115}$ In a recent systematic review, Chiesa and Serretti ${ }^{116}$ found promising results regarding the impact of $\mathrm{MM}$ on brain regions and activity that are typically associated with relaxation. Neuroimaging and electroencephalography (EEG) studies showed changes in activation of PFC and the anterior cingulate cortex (ACC), as well as significant increases in alpha and theta activity during meditation. This pattern of activation is commonly associated with meditation and relaxation. ${ }^{114}$ In addition, theta activity was found to be more common in experienced meditators, suggesting that greater MM expertise may result in improved ability to self-regulate a state of deep relaxation. These findings are important because they demonstrate a neurobiological impact of MM on brain structures and regions (ie, PFC, hippocampus, limbic system) that are well-known to be affected in individuals with depression and chronic stress. ${ }^{68}$

In a study of a mindfulness intervention on attention regulation, Jha et $\mathrm{al}^{117}$ found that participants who received an 8-week MBSR intervention demonstrated improved ability to focus attention on the present moment, as measured by performance on a laboratory attention task. Similarly, Tang et al found that participation in 5 days of integrative meditation practice, including mindfulness training, resulted in improved efficiency regarding executive attention during a computerized attention task compared to control participants who did not receive meditation training. ${ }^{118}$ Imaging studies have demonstrated changes in the PFC, which is associated with attention, concentration, and emotion regulation, in those with greater (existing) mindfulness skills, and for those who receive MBSR training. Specifically, Creswell et al ${ }^{119}$ found that individuals with heightened mindfulness abilities show less emotional reactivity in the midbrain (amygdala, dorsal ACC), which is likely due to an enhanced ability to engage the PFC. In a study of an 8-week MBSR intervention in a corporate setting, changes in electrical (EEG) activity in the forebrain were found when positive emotions (eg, joy) were experienced. ${ }^{120}$ Functional magnetic resonance imaging (MRI) studies have suggested increased neuronal activity in regions of the brain related to self-awareness (eg, dorsolateral and medial PFC), particularly momentary self-awareness/self-reference for individuals completing an 8-week MBSR compared to novice controls. ${ }^{121}$ In a recent structural MRI study, researchers found that experienced meditators had more gray matter in regions of the brain thought to underlie interoceptive awareness (eg, right anterior insula). ${ }^{122}$ Other findings ${ }^{123}$ suggest that the beneficial effects of mindfulness training, including meditation, may be linked with the level of skill in the practicing meditator. Specifically, some studies ${ }^{123,124}$ have shown that, when compared to nonmeditators, skilled meditators demonstrate increased brain activation in the rostral $\mathrm{ACC}$ and dorsomedial PFC during a mindful breathing task (compared to a focused mental arithmetic task). This difference is suggestive of more adept processing of distraction and emotions in skilled meditators versus individuals who do not meditate. ${ }^{124}$ Generally, recent brain imaging data suggest that focused, concentrative meditation (eg, mindful breathing meditation, loving-kindness meditation) may improve an individual's ability to sustain attention on a chosen object; however, meditation practices emphasizing open awareness may improve the ability to flexibly monitor and redirect attention. ${ }^{115}$ These findings are important, as they show promise for the ability of individuals to train the mind, changing not only emotional experiences, but also brain structure and functioning; moreover, the ability to do so appears to improve over time as experience with meditation increases. This suggests that MM may have the ability to positively impact the long-term maintenance of improved mood states and emotional functioning via long-term structural and functional changes in the brain, thereby offering the potential for prevention of clinical levels of psychopathology and improving overall psychological well-being in nonclinical samples.

\section{Summary and future directions}

While research on the effects of mindfulness training and meditation has traditionally been limited by methodological weaknesses to date, findings regarding the potential for mindfulness interventions to reduce various problematic conditions, such as pain, stress, anxiety, depression (relapse), and disordered eating, are promising. . $^{14,21,29,49,59,64,82,125}$ The most 
recent data has demonstrated the beneficial effects on physical and psychological health and well-being. ${ }^{8,51,59,82}$ Moreover, the research suggests that mechanisms that are responsible for these effects involve not only relaxation, but also shifts in cognitive patterns, emotional processing, biology, and behavior that interact to create improvements in health, quality of life, and ability to engage in meaningful relationships with others. Studies in the basic sciences have also provided important evidence that mindfulness training may result in important changes in brain functioning and structures that are associated with improved emotional well-being in the short- and long-term.

Overall, the available literature suggests that MBIs, which include MM practices, may represent viable approaches to the treatment of symptoms of anxiety and depression in both clinical and nonclinical populations. However, given the early stage of this line of research and methodological limitations of available studies, the generalizability of the findings is difficult. In addition, the ability to draw conclusions regarding the causal relationships between $\mathrm{MM}$ and the observed effects/improvements are limited by methodological challenges, including liberal inclusion criteria, overlapping symptoms that may impact depression or anxiety severity scores (eg, physical symptoms of illness such as fatigue that may be reported on a mood scale) and poorly controlled trials. Nonetheless, findings are promising regarding the efficacy of mindfulness training as it relates to symptom reduction and improved overall psychological well-being. Additional research is needed to determine the efficacy and effectiveness of mindfulness interventions as independent treatment approaches for both the symptoms of anxiety and depression, as well as anxiety and depressive disorders as diagnosed by DSM criteria. Additional research is also needed to determine whether outcomes change/improve when paired with more traditional therapies (eg, psychotropic medications). Moreover, further research is needed to clarify the mechanisms of change, dose-response relationship issues, and issues regarding which components of mindfulness training are most important in differing populations (eg, primary psychological disorders, psychological distress secondary to physical disease). In addition, longitudinal studies are needed to explore the sustained benefits of mindfulness. It is possible that regular mindfulness practice may alter existing personality traits or, conversely, existing personality traits may impede the regular practice of mindfulness. More research is needed to explore these factors, as well as whether changes in personality traits and degree of use of everyday mindfulness are differentially effective in producing improvements to psychological well-being.
Regardless of the various limitations present in the available literature, findings to date have consistently demonstrated that training focused on improving attention, awareness, acceptance, and compassion may facilitate more flexible and adaptive responses to stress. Greater understanding of these findings has the potential to result in translation of empirical findings into more effective clinical practice in the treatment of anxiety and depression. Moreover, increased collaboration in the study of how MM may work to effect positive changes on psychological well-being may ultimately, and, possibly more importantly, result in an improved ability to disseminate information that may result in the prevention of the development of clinical psychiatric disorders, thereby improving health, life satisfaction, well-being, and overall quality of life.

\section{Disclosure}

The authors report no conflicts of interest in this work.

\section{References}

1. Barbour KA, Edenfield TM, Blumenthal JA. Exercise as a treatment for depression and other psychiatric disorders: a review. J Cardiopulm Rehabil Prev. 2007;27(6):359-367.

2. Benson H, Klipper MZ. The Relaxation Response. New York, NY: Harpertorch; 1975.

3. Camacho TC, Roberts RE, Lazarus NB, Kaplan GA, Cohen RD. Physical activity and depression: evidence from the Alameda county study. Am J Epidemiol. 1991;134:220-231.

4. Cameron OG, Hudson, CJ. Influence of exercise on anxiety level in patients with anxiety disorders. Psychosomatics. 1986;27:720-723.

5. Dunn AL, Trivedi MH, Kampert JB, Clark CG, Chambliss HO. Exercise treatment for depression: efficacy and dose response. Am J Prev Med. 2005;28:1-8.

6. Baer RA. Mindfulness training as a clinical intervention: a conceptual and empirical review. Clin Psychol SCI-PR. 2003;10:125-143.

7. Bohlmeijer E, Prenger R, Taal E, Cuijpers P. The effects of mindfulnessbased stress reduction therapy on mental health of adults with a chronic medical disease: a meta-analysis. J Psychosom Res. 2010;68(6):539-544.

8. Greeson JM. Mindfulness research update: 2008. Complement Health Pract Rev. 2009;14(1):10-18.

9. Hofmann SG, Sawyer AT, Witt AA, Oh D. The effect of mindfulnessbased therapy on anxiety and depression: A meta-analytic review. J Consult Clin Psychol. 2010;78(2):169-183.

10. Antonacci DJ, Davis E, Bloch RM, Manuel C, Saeed SA. CAM for your anxious patient: what the evidence says. Curr Psychiatr. 2010;9(10):43-52.

11. Saeed SA, Bloch RM, Antonacci DJ, Davis CE, Manuel C. CAM for your depressed patient: 6 recommended options. Curr Psychiatr. 2009;8(10):39-47.

12. Kessler RC, Soukup J, Davis RB, et al. The use of complementary and alternative therapies to treat anxiety and depression in the United States. Am J Psychiatry. 2001;158(2):289-294.

13. Segal ZV, Williams JMG, Teasdale JD. Mindfulness-Based Cognitive Therapy for Depression: A New Approach to Preventing Relapse. New York, NY: Guilford Press; 2002.

14. Kabat-Zinn J, Massion AO, Kristeller J, Peterson LG. Effectiveness of a meditation-based stress reduction program in the treatment of anxiety disorders. Am J Psychiatry. 1992;149:936-943.

15. Bishop SR, Lau M, Shapiro S, et al. Mindfulness: a proposed operational definition. Clin Psychol (New York). 2004;11(3):230-241.

16. Hayes SC. Acceptance and commitment therapy, relational frame theory, and the third wave of behavior therapy. Behav Ther. 2004;35:639-665. 
17. Kabat-Zinn J. Wherever You Go There You Are. New York, NY: Hyperion; 1994.

18. Salmon P, Lush E, Jablonski M, Sephton SE. Yoga and mindfulness: clinical aspects of an ancient mind/body practice. Cogn Behav Pract. 2009;16:59-72.

19. Toneatto T, Ngyuen L. Does mindfulness meditation improve anxiety and mood symptoms? A review of the controlled research. Can J Psychiatry. 2007;52(4):260-266.

20. Kristeller J, Baer R, Quillian-Wolever R. Mindfulness-based approaches to eating disorders. In: Baer RA, editor. Mindfulness-based Treatment Approaches. San Diego, CA: Elsevier; 2006.

21. Kristeller J, Baer R, Quillian-Wolever R. Effects of a meditationbased intervention in the treatment of binge eating. $J$ Health Psychol. 1999;4(3):357-363.

22. Bowen S, Witkiewitz K, Dillworth TM, et al. Mindfulness meditation and substance use in an incarcerated population. Psychol Addict Behav. 2006;20:343-347.

23. Kabat-Zinn J. Full Catastrophe Living: Using the Wisdom OfYour Body And Mind To Face Stress, Pain, And Illness. New York: NY: Delacorte Press; 1990.

24. Hayes SC, Strosahl KD, Wilson KG. Acceptance and Commitment Therapy: An Experiential Approach To Behavior Change. New York: Guilford Press; 1999.

25. Linehan MM. Skills Training Manual For Treating Borderline Personality Disorder. New York, NY: Guilford Press; 1993.

26. Chiesa A, Malinowski P. Mindfulness-based approaches: are they all the same? J Clin Psychol. 2011;67(4):404-424.

27. Rapgay L, Bystrisky A. Classical mindfulness: an introduction to its theory and practice for clinical application. Ann N Y Acad Sci. 2009;1172:148-162.

28. Goleman DJ, Schwartz GE. Meditation as an intervention in stress reactivity. J Consult Clin Psychol. 1976;44:456-466.

29. Kabat-Zinn J. An outpatient program in behavioral medicine for chronic pain patients based on the practice of mindfulness meditation theoretical considerations and preliminary results. Gen Hosp Psychiatry. 1982;4:33-47.

30. Cuijpers P, Smit F, Bohlmeijer E, Hollon SD, Andersson G. Efficacy of cognitive-behavioural therapy and other psychological treatments for adult depression: meta-analytic study of publication bias. $\mathrm{Br} J$ Psychiatry. 2010;196(3):173-178.

31. Benson H, Alexander S, Feldman CL. Decreased premature ventricular contractions through use of the relaxation response in patients with stable ischaemic heart-disease. Lancet. 1975;2(7931):380-382.

32. Benson H, Dryer T, Hartley LH. Decreased VO2 consumption during exercise with elicitation of the relaxation response. J Human Stress. 1978;4(2):38-42.

33. Benson H, Frankel FH, Apfel R, et al. Treatment of anxiety: a comparison of the usefulness of self-hypnosis and a meditational relaxation technique. An overview. Psychother Psychosom. 1978;30(3-4):229-242.

34. Benson H, Kotch JB, Crassweller KD. Stress and hypertension: interrelations and management. Cardiovasc Clin. 1978;9(1):113-124.

35. Lazar SW, Bush G, Gollub RL, Fricchione GL, Khalsa G, Benson H. Functional brain mapping of the relaxation response and meditation. Neuroreport. 2000;11(7):1581-1585.

36. Delmonte MM. Meditation and anxiety reduction: a literature review. Clin Psychol Rev. 1985;5:91-102.

37. Smith J. Meditation and psychotherapy: a review of the literature Psychol Bull. 1975;32:553-564.

38. Kabat-Zinn J. Mindfulness-based interventions in context: past, present, and future. Clin Psychol (New York). 2003;10(2):144-156.

39. Allen NB, Chambers R, Knight W; Melbourne Academic Mindfulness Interest Group. Mindfulness-based psychotherapies: a review of conceptual foundations, empirical evidence and practical considerations. Aust N Z J Psychiatry. 2006;40:285-294.

40. Marlatt GA, Kristeller JL. Mindfulness and meditation. In: Miller WR, editor. Integrating Spirituality into Treatment. Washington, DC: American Psychological Association; 1999:67-84.
41. Analayo. Satipatthana: the Direct Path to Realization. Birmingham, UK: Windhorse Publications; 2003.

42. Hayes SC, Luoma JB, Bond FW, Masuda A, Lillis J. Acceptance and commitment therapy: model, processes and outcomes. Behav Res Ther. 2006;44(1):1-25.

43. Carmody J, Baer RA. How long does a mindfulness-based stress reduction program need to be? A review of class contact hours and effect sizes for psychological distress. J Clin Psychol. 2009;65:627-638.

44. Mackenzie MJ, Carlson LE, Speca M. Mindfulness-based stress reduction (MBSR) in oncology: rationale and review. Evidence-based Integrative Medicine. 2005;2:139-145.

45. Matchim Y, Armer JM. Measuring the psychological impact of mindfulness meditation on health among patients with cancer: a literature review. Oncol Nurs Forum. 2007;34:1059-1066.

46. Ott MJ, Norris RL, Bauer-Wu SM. Mindfulness meditation for oncology patients: a discussion and critical review. Integr Cancer Ther. 2006;5(2):98-108

47. Praissman S. Mindfulness-based stress reduction: a literature review and clinician's guide. J Am Acad Nurse Pract. Apr 2008;20(4):212-216.

48. Smith JE, Richardson J, Hoffman C, Pilkington K. Mindfulness-Based Stress Reduction as supportive therapy in cancer care: systematic review. J Adv Nurs. 2005;52(3):315-327.

49. Teixeira ME. Meditation as an intervention for chronic pain: an integrative review. Holistic Nurse Practitioner. 2008;22:225-234.

50. Winbush NY, Gross CR, Kreitzer MJ. The effects of mindfulnessbased stress reduction on sleep disturbance: a systematic review. Explore (NY). 2007;3:585-591.

51. Grossman P, Niemann L, Schmid S, Walach H. Mindfulness-based stress reduction and health benefits: a meta-analysis. J Psychosom Res. 2004;57:35-43.

52. Ledesma D, Kumano H. Mindfulness-based stress reduction and cancer: a meta-analysis. Psychooncology. 2008;18:571-579.

53. Morone NE, Greco CM, Weiner DK. Mindfulness meditation for the treatment of chronic low back pain in older adults: a randomized controlled pilot study. Pain. 2008;134:310-319.

54. Grossman P, Tiefenthaler-Gilmer U, Raysz A, Kesper U. Mindfulness training as an intervention for fibromyalgia: evidence of postintervention and 3-year follow-up benefits in well-being. Psychother Psychosom. 2007;76:226-233.

55. Pradhan EK, Baumgarten M, Langenberg P1, et al. Effect of mindfulnessbased stress reduction in rheumatoid arthritis patients. Arthritis Rheum. 2007;57:1134-1142.

56. Zautra AJ, Davis MC, Reich JW, et al. Comparison of cognitive behavioral and mindfulness meditation interventions on adaptation to rheumatoid arthritis for patients with and without history of recurrent depression. J Consult Clin Psychol. 2008;76:408-421.

57. Kabat-Zinn J, Wheeler E, Light $\mathrm{T}$, et al. Influence of a mindfulness meditation-based stress reduction intervention on rates of skin clearing in patients with moderate to severe psoriasis undergoing phototherapy (UVB) and photochemotherapy (PUVA). Psychosom Med. 1998;60:625-632.

58. Rozenzweig S, Reibel DK, Greeson JM, et al. Mindfulness-based stress reduction is associated with improved glycemic control in type 2 diabetes mellitus: a pilot study. Altern Ther Health Med. 2007;13: 36-38.

59. Chiesa A, Serretti A. Mindfulness-based interventions for chronic pain: a systematic review of the evidence. J Altern Complement Med. 2011;17(1):83-93

60. Brown KW, Ryan RM, Creswell JD. Mindfulness: theoretical foundations and evidence for salutary effects. Psychol Inq. 2007;18:211-237.

61. Ludwig DS, Kabat-Zinn J. Mindfulness in medicine. J Am Med Assoc. 2008;300:1350-1352.

62. Shigaki CL, Glass B, Schopp LH. Mindfulness-based stress reduction in medical settings. J Clin Psychol Med Settings. 2006;13:209-216.

63. Garland EL. The meaning of mindfulness: a second-order cybernetics of stress, metacognition, and coping. Complement Health Pract Rev. 2007; 12:15-30. 
64. Teasdale JD, Williams JM, Soulsby JM, Segal ZV, Ridgeway VA, Lau MA. Prevention of relapse/recurrence in major depression by mindfulness-based cognitive therapy. J Consult Clin Psychol. 2000;68: 615-623.

65. Shapiro SL, Carlson LE, Astin JA, Freedman B. Mechanisms of mindfulness. J Clin Psychol. 2006;62:373-386.

66. Garland E, Gaylord S, Park J. The role of mindfulness in positive reappraisal. Explore (NY). 2009;5:37-44.

67. Ortner CNM, Kilner SJ, Zelazo PD. Mindfulness meditation and reduced emotional interference on a cognitive task. Motiv Emot. 2007:31:271-283.

68. Hill MN, Hellemans KG, Verma P, Gorzalka BB, Weinberg J. The neurobiology of chronic mild stress: parallels to major depression. Br Med Bull. 2012;101:127-145.

69. Brown MR, Fisher LA. Corticotropin-releasing factor: effects on the autonomic nervous system and visceral systems. Fed Proc. 1985;44:243-248.

70. Arborelius L, Owens MJ, Plotsky PM, Nemeroff CB. The role of corticotrophin-releasing factor in depression and anxiety disorders. J Endocrinol. 1999;160:1-12.

71. Crespi EJ, Denver RJ. Ancient origins of human developmental plasticity. Am J Hum Biol. 2005;17:44-54.

72. Dallman MF, Hellhammer D. Regulation of the hypothalamo-pituitaryadrenal axis, chronic stress, and energy: the role of brain networks. In: Baum A, Contrada R, editors. The Handbook of Stress Science: Biology, Psychology, and Health. New York, NY: Springer; 2010: 11-36.

73. Gold PW, Chrousos GP. Organization of the stress system and its dysregulation in melancholic and atypical depression: high vs low CRH/NE states. Mol Psychiatry. 2002;7:254-275.

74. Rozanski A, Blumenthal JA, Davidson KW, Saab PG, Kubzansky L. The epidemiology, pathophysiology, and management of psychosocial risk factors in cardiac practice. $J$ Am Coll Cardiol. 2005;45: 637-651.

75. Greeson J, Brantley J. Mindfulness and anxiety disorders: Developing a wise relationship with the inner experience of fear. In: Didonna F, editor. Clinical Handbook of Mindfulness. New York, NY: Springer; 2008:171-188.

76. Chiesa A, Calati R, Serretti A. Does mindfulness training improve cognitive abilities? A systematic review of neuropsychological findings. Clin Psychol Rev. 2011;31:449-463.

77. Kumar SM, Feldman GC, Hayes A. Changes in mindfulness end emotion regulation in an exposure based cognitive therapy for depression. Cognit Ther Res. 2008;32:734-744.

78. Raes F, Dewulf D, Van Heeringen C, Williams JM. Mindfulness and reduced cognitive reactivity to sad mood: evidence from a correlational study and a non-randomized waiting list controlled study. Behav Res Ther. 2009;47:623-627.

79. Leichsenring F, Rabung S. Effectiveness of long-tern psychodynamic psychotherapy: a meta-analysis. JAMA. 2008;300:1551-1565.

80. Leichsenring F, Rabung S, Leibing E. The efficacy of short-term psychodyamic psychotherapy in specific psychiatric disorders: a metaanalysis. Arch Gen Psychiatry. 2004;61:1208-1216.

81. Smits AJ, Hoffman SG. A meta-analytic review of the effects of psychotherapy control conditions for anxiety disorders. Psychol Med. 2009;39:229-239.

82. Keng SL, Smoski MJ, Robins CJ. Effects of mindfulness on psychological health: a review of empirical studies. Clin Psychol Rev. 2011;31:1041-1056.

83. Just N, Alloy LB. The response styles theory of depression: tests and an extension of the theory. J Abnorm Psychol. 1997;106:221-229.

84. Nolen-Hoeksema S. The role of rumination in depressive disorders and mixed anxiety/depressive symptoms. J Abnorm Psychol. 2000;109:504-511.

85. Spasojevic J, Alloy LB. Rumination as a common mechanism relating depressive risk factors to depression. Emotion. 2001;1:25-37.
86. Carmody J, Baer RA. Relationships between mindfulness practice and levels of mindfulness, medical and psychological symptoms and well-being in a mindfulness-based stress reduction program. J Behav Med. 2008;31:23-33.

87. Jain S, Shapiro SL, Swanick S, et al. A randomized controlled trial of mindfulness meditation versus relaxation training: effects on distress, positive states of mind, rumination, and distraction. Ann Behav Med. 2007;33:11-21.

88. Ramel W, Goldin PR, Carmona PE, McQuaid JR. The effects of mindfulness meditation training on cognitive processes and affect in patients with past depression. Cognit Ther Res. 2004;28: 433-455.

89. Deyo M, Wilson KA, Ong J, Koopman C. Mindfulness and rumination: does mindfulness training lead to reductions in the ruminative thinking associated with depression? Explore. 2009;5(5): 265-271.

90. Feldman G, Hayes A, Kumar S, Greeson J, Laurenceau JP. Mindfulness and emotional regulation: the development and initial validation of the Cognitive and Affective Mindfulness Scale-Revised (CAMS-R). J Psychopathol Behav Assess. 2007;29:177-190.

91. Baer RA, Smith GT, Hopkins J, Krietemeyer J, Toney L. Using self-report assessment methods to explore facets of mindfulness. Assessment. 2006;13:27-45.

92. Brown KW, Ryan RM. The benefits of being present: mindfulness and its role in psychological well-being. J Pers Soc Psychol. 2003;84:822-848.

93. Cardaciotto L, Herbert JD, Forman EM, Moitra E, Farrow V. The assessment of present-moment awareness and acceptance: the Philadelphia mindfulness scale. Assessment. 2008;15:204-223.

94. Walach H, Buchheld N, Buttenmuller V, Kleinknecht N, Schmidt S. Measuring mindfulness - The Freiburg Mindfulness Inventory. Pers Individ Dif. 2006;40:1543-1555.

95. Thompson BL, Waltz J. Everyday mindfulness and mindfulness meditation: overlapping constructs or not? Pers Individ Dif. 2007;43:1875-1885.

96. Baer RA, Smith GT, Lykins E, et al. Construct validity of the five facet mindfulness questionnaire in meditating and nonmeditating samples. Assessment. 2008:15:329-342.

97. Lau MA, Bishop SR, Segal ZV, et al. The Toronto Mindfulness Scale: Development and validation. J Clin Psychol. 2006;62: 1445-1467.

98. Davis JM, Fleming MF, Bonus KA, Baker TB. A pilot study on mindfulness based stress reduction for smokers. BMC Complement Altern Med. 2007;7:2.

99. Brand S, Holsboer-Trachsler E, Naranjo JR, Schmidt S. Influence of mindfulness practice on cortisol and sleep in long-term and short-term meditators. Neuropsychobiology. 2012;65:109-118.

100. Roemer L, Orsillo SM. Mindfulness: a promising intervention strategy in need of further study. Clin Psychol (New York). 2003;10: 144-156.

101. Williams JMG. Mindfulness, depressoin, and modes of mind. Cognit Ther Res. 2008;32:721-733.

102. Frewen P, Evans E, Maraj N, Dozois D, Partridge K. Letting go: mindfulness and negative automatic thinking. Cognit Ther Res. 2008;32(6):758-774.

103. Feldman G, Greeson J, Senville J. Differential effects of mindful breathing, progressive muscle relaxation, and loving-kindness meditation on decentering and negative reactions to repetitive thoughts. Behav Res Ther. 2010;48(10):1002-1011.

104. Stathopoulou G, Powers MB, Berry AC, Smits JAJ, Otto M. Exercise interventions for mental health: a quantitative and qualitative review. Clin Psychol (New York). 2006;13:179-193.

105. Dunn AL, Trivedi MH, Kampert JB, Clark CG, Chambliss HO. The DOSE study: a clinical trial to examine efficacy and dose response of exercise as a treatment for depression. Control Clin Trials. 2002;23:584-603. 
106. Lawlor DA, Hopker SW. The effectiveness of exercise as an intervention in the management of depression: systematic review and meta-regression analysis of randomised controlled trials. BMJ. 2001;322(7289):763-767.

107. Salmon P, Lush E, Jablonski M, Sephton SE. Effects of physical exercise on anxiety, depression, and sensitivity to stress: a unifying theory. Clin Psychol Rev. 2001;21(1):33-61.

108. Yusuf S, Hawken S, Ounpuu S, et al. Effect of potentially modifiable risk factors associated with myocardial infarction in 52 countries (the INTERHEART study): case-control study. Lancet. 2004;364: 937-952.

109. Warburton DER, Nicol CW, Bredin SSD. Health benefits of physical activity: the evidence. CMAJ. 2006;174:801-809.

110. Scully D, Kremer J, Meade MM, Graham R, Dudgeon K. Physical exercise and psychological well being: a critical review. Br J Sports Med. 1998;32:111-120.

111. Freitas-Ferrari MC, Hallak JE, Trzesniak C, et al. Neuroimaging in social anxiety disorder: a systematic review of the literature. Progress in Neuropsychopharmacology and Biological Psychiatry. 2010;34(4): 565-580.

112. Palazidou E. The neurobiology of depression. Br Med Bull. 2012;101:127-145.

113. Yassa MA, Hazlett RL, Stark CE, Hoehn-Saric R. Functional MRI of the amygdala and bed nucleus of the stria terminalis during conditions of uncertainty in generalized anxiety disorder. J Psychiatr Res. 2012;46(8):1045-1052.

114. Cahn BR, Polich J. Meditation states and traits: EEG, ERP, and neuroimaging studies. Psychol Bull. 2006;132:180-211.

115. Lutz A, Slagter HA, Dunne JD, Davidson RJ. Attention regulation and monitoring in meditation. Trends Cogn Sci. 2008;12:163-169.
116. Chiesa A, Serretti A. A systematic review of neurobiological and clinical features of mindfulness meditations. Psychol Med. 2010;40:1239-1252.

117. Jha AP, Krompinger J, Baime MJ. Mindfulness training modifies subsystems of attention. Cogn Affect Behav Neurosci. 2007;7:109-119.

118. Tang YY, MaY, Wang J, et al. Short-term meditation training improves attention and self-regulation. Proc Natl Acad Sci U S A. 2007;104: 17152-17156.

119. Creswell JD, May BM, Eisenberger NI, Lieberman MD. Neural correlates of dispositional mindfulness during affect labeling. Psychosom Med. 2007;69:560-565.

120. Davidson RJ, Kabat-Zinn J, Schumacher J, et al. Alterations in brain and immune function produced by mindfulness meditation. Psychosom Med. 2003;65(4):564-570.

121. Farb NAS, Segal ZV, Mayberg H, et al. Attending to the present: mindfulness meditation reveals distinct neural modes of self-reference. Soc Cogn Affect Neurosci. 2007;2:313-322.

122. Holzel BK, Ott U, Gard T, et al. Investigation of mindfulness meditation practiitoners with voxel-based morphometry. Soc Cogn Affect Neurosci. 2007;3:55-61.

123. Lutz A, Brefczynski J, Johnstone T, Davidson RJ. Regulation of neural circuitry of emotion by compassion meditation: effects of meditative expertise. PLoS ONE. 2008;3(3):e1897.

124. Holzel BK, Ott U, Hempel H, et al. Differential engagement of anterior cingulate and adjacent medial frontal cortex in adept meditators and non-meditators. Neurosci Lett. 2007;421:16-21.

125. Shapiro SL, Schwartz GE, Bonner G. Effects of mindfulness-based stress reduction on medical and premedical students. J Behav Med. 1998;21:581-599.
Psychology Research and Behavior Management

\section{Publish your work in this journal}

Psychology Research and Behavior Management is an international, peerreviewed, open access journal focusing on the science of psychology and its application in behavior management to develop improved outcomes in the clinical, educational, sports and business arenas. Specific topics covered include: Neuroscience, memory \& decision making; Behavior

\section{Dovepress}

modification \& management; Clinical applications; Business \& sports performance management; Social and developmental studies; Animal studies. The manuscript management system is completely online and includes a quick and fair peer-review system. Visit http://www.dovepress. com/testimonials.php to read real quotes from published authors. 